\title{
Analysis of clinic attendances by under-14s to sexual health clinics in Gwent, South Wales, UK
}

\author{
Louise Cook, Charlotte Fleming
}

\begin{abstract}
Objectives To determine the gender, sexual history and reason(s) for visit for under-14s (young people) attending the authors' sexual health clinics.

Methods Analysis of case notes of 242 young people who made a total of 598 visits to a sexual health clinic in Gwent, South Wales, UK between 1 January and 31 December 2003.

Results Of the 242 young people studied, $41 \%$ were male and males were responsible for $42 \%$ of visits. There was no written record relating to $7 \%$ of the total visits. Median age at both first registration and first heterosexual intercourse (when recorded) was 12 years for males and 13 years for females. Some $57 \%$ of females and $30 \%$ of males were already sexually active at first registration. Details relating to a young person's partner and their experience of sex (e.g. willingness, autonomy and consensual nature of sex) were infrequently recorded, especially for males. $96 \%$ of males requested condoms
\end{abstract}

\section{Introduction}

Under the Sexual Offences Act $2003^{1}$ all teenagers, including those aged under 13 years, are entitled to receive confidential sexual health advice and contraception. The Bichard Inquiry has called for vigilance when consulting with sexually active young people with the reporting of all suspected criminal activities to the police. ${ }^{2}$ Bichard himself has subsequently emphasised that these recommendations were not intended to criminalise young people in nonabusive teenage relationships. ${ }^{3}$ London and Sheffield Area Child Protection Committees require that health professionals automatically report all sexually active under-13s and the partners of teenagers aged under 16 years to the police. ${ }^{4}$ However, a multi-agency response to these proposals warns against such compulsory reporting, but stresses the importance of making an appropriate 'risk assessment' of potentially vulnerable young people.

In 2003, the authors' service held a meeting with police, outreach and social services at which concerns were raised over the vulnerability of a minority of young people who attend its clinics. In response, we undertook a review of the case notes in order to determine how much we know about our clients' sexual histories and their use of our services. Under-14s were chosen because they fall below the Welsh national average age at first heterosexual intercourse (sexual debut) of 14.3 years. ${ }^{6}$ This is lower than the UK average and may reflect a lower age at sexual debut with lower social class; ${ }^{7}$ teenage motherhood is higher in Wales than England and cultural expectations may be different.

Risca Surgery, Risca, Newport, UK

Louise Cook, MRCGP, DFFP, General Practitioner

Sexual and Reproductive Health Directorate, Gwent

Healthcare NHS Trust, Cwmbran, UK

Charlotte Fleming, MD, MRCOG, Consultant

Correpondence to: Dr Charlotte Fleming, Sexual and Reproductive Health Directorate, Gwent Healthcare NHS Trust Llanyrafon House, Llanfrechfa Grange, Cwmbran, Gwent NP44 8YN, UK. E-mail: charlotte.fleming@gwent.wales.nhs.uk and $99 \%$ received them, whilst $72 \%$ of females requested condoms and/or hormonal contraception and $86 \%$ received them. $35 \%$ of females were seen for the consequences of sex (i.e. pregnancy testing, emergency contraception, screening and/or treatment of sexually transmitted infections and unplanned pregnancies). $80 \%$ of these subsequently received condoms and/or hormonal contraception. The majority of young people saw a nurse exclusively ( $96 \%$ males, $71 \%$ females).

Conclusions Of the young clients seen, $41 \%$ are male. Sexual history details are infrequently recorded, particularly for males. The majority of young people accessing the authors' service are taking action to protect their sexual health and most will see a nurse exclusively.

Keywords clinic attendance, contraception, sexual health, sexually transmitted infections, young people

J Fam Plann Reprod Health Care 2007; 33(1): 23-26 (Accepted 11 April 2006)

Key message points

- Record keeping needs refocusing to be gender neutral and to prompt recording of sexual history.

- The majority of young people accessing the authors services are taking action to protect their sexual health.

- Nursing staff see the majority of under-14s; training resources need to be directed accordingly.

Also the method of questioning (examination setting in Welsh youth survey) may have encouraged different responses to those in other surveys. This paper reports the findings relating to a young person's sex, their sexual history and reason for visit. Data relating to identifying the risk of sexual abuse and exploitation and to the recording of compliance with Fraser competence is reported elsewhere. ${ }^{8}$

\section{Background}

Gwent Sexual Health Service provides 47 walk-in clinics at 26 sites each week. Of these, 13 are young peoples' clinics (YPCs) catering to under-25s. The remaining family planning clinics (FPCs) can be accessed by clients of any age. The C-card scheme, funded by the Welsh Assembly Government, distributes free condoms and supporting literature to young people aged 14-25 years. Although independent of our own clinics, we facilitate its operation and the scheme often shares a session with a YPC.

\section{Methods}

Case notes of all under-14s (young people) who attended a clinic between 1 January and 31 December 2003 were reviewed and the data were recorded on a data collection template. The data were analysed using Microsoft Excel ${ }^{\mathrm{TM}}$.

\section{Results}

Some 242 young people made a total of 598 visits to a sexual health clinic during 2003. Males accounted for $41 \%$ of young people and $42 \%$ of total visits. Males were more likely to attend a YPC than an FPC (62\% vs $38 \%)$. There was less variation for females ( $46 \%$ vs $54 \%$ ). 
Table 1 Age of young person at first registration with service and at each visit during 2003

\begin{tabular}{|c|c|c|c|c|c|c|c|c|}
\hline \multirow[t]{3}{*}{ Age (years) } & \multicolumn{4}{|c|}{ Age at first registration with service ${ }^{a}$} & \multicolumn{4}{|c|}{ Age at visit during study period } \\
\hline & \multicolumn{2}{|c|}{ Males } & \multicolumn{2}{|c|}{ Females } & \multicolumn{2}{|c|}{ Male visits } & \multicolumn{2}{|c|}{ Female visits } \\
\hline & $n$ & $\%$ & $n$ & $\%$ & $n$ & $\%$ & $n$ & $\%$ \\
\hline $\begin{array}{l}<11 \\
11 \\
12 \\
13 \\
14 \mathrm{~b} \\
\text { Total }\end{array}$ & $\begin{array}{r}2 \\
10 \\
47 \\
41\end{array}$ & $\begin{array}{r}2 \\
10 \\
47 \\
41\end{array}$ & $\begin{array}{r}3 \\
9 \\
27 \\
103\end{array}$ & $\begin{array}{r}2 \\
6 \\
19 \\
73\end{array}$ & $\begin{array}{r}0 \\
3 \\
85 \\
154 \\
12 \\
254\end{array}$ & $\begin{array}{r}0 \\
1 \\
33 \\
61 \\
5 \\
100\end{array}$ & $\begin{array}{r}1 \\
7 \\
29 \\
271 \\
36 \\
344\end{array}$ & $\begin{array}{r}2 \\
8 \\
79 \\
11 \\
100\end{array}$ \\
\hline
\end{tabular}

aRefers to first registration with service which may have taken place prior to or during 2003.

bSome young people who attended during 2003 were seen both before and after their fourteenth birthday.

Table 2 Frequency distribution of visits made by both sexes during 2003

\begin{tabular}{|c|c|c|c|c|c|c|c|c|c|c|c|c|c|c|c|c|c|c|}
\hline \multirow[t]{2}{*}{ Gender $(n)$} & \multicolumn{17}{|c|}{ Frequency of visits $(n)$} & \multirow[t]{2}{*}{ Total $(n)$} \\
\hline & 1 & 2 & 3 & 4 & 5 & 6 & 7 & 8 & 9 & 10 & 11 & 12 & 13 & 14 & 15 & 16 & 17 & \\
\hline $\begin{array}{l}\text { Male } \\
\text { Female } \\
\text { Total }\end{array}$ & $\begin{array}{r}40 \\
72 \\
112\end{array}$ & $\begin{array}{l}29 \\
28 \\
57\end{array}$ & $\begin{array}{l}16 \\
14 \\
30\end{array}$ & $\begin{array}{r}5 \\
9 \\
14\end{array}$ & $\begin{array}{l}2 \\
5 \\
7\end{array}$ & $\begin{array}{r}2 \\
8 \\
10\end{array}$ & $\begin{array}{l}1 \\
2 \\
3\end{array}$ & $\begin{array}{l}1 \\
1 \\
2\end{array}$ & $\begin{array}{l}0 \\
0 \\
0\end{array}$ & $\begin{array}{l}1 \\
0 \\
1\end{array}$ & $\begin{array}{l}0 \\
1 \\
1\end{array}$ & $\begin{array}{l}0 \\
0 \\
0\end{array}$ & $\begin{array}{l}1 \\
0 \\
1\end{array}$ & $\begin{array}{l}2 \\
0 \\
2\end{array}$ & $\begin{array}{l}0 \\
1 \\
1\end{array}$ & $\begin{array}{l}0 \\
0 \\
0\end{array}$ & $\begin{array}{l}0 \\
1 \\
1\end{array}$ & $\begin{array}{l}100 \\
142 \\
242\end{array}$ \\
\hline
\end{tabular}

Median age at first registration for males was 12 (range, 10-13) years and for females 13 (range, 8-13) years. One third of males and $10 \%$ of females were aged 12 years or younger when seen in 2003 (Table 1). The median number of visits for males was two (range, 1-14) and for females one (range, 1-17). Twelve young people were responsible for $5 \%$ of the visits, each being seen on seven or more occasions (Table 2).

Sexual status at first registration with the service was recorded for $78 \%$ of males and $93 \%$ of females, with $30 \%$ of males and $57 \%$ of females already sexually active. Age at sexual debut was identified for $23 \%$ of males and $44 \%$ of females (Table 3). A further $9 \%$ of both sexes became sexually active between first registration and a follow-up visit in 2003. Median age at sexual debut (when recorded) was 12 years for males and 13 years for females.

Where the young person was known to be sexually active, the number of partners could be determined for $9 \%$ of visits, $70 \%$ of these related to female clients. For this $9 \%$, median number of partners for females was two (range, 1-5) and for males one (range, 1-3).

Age of partner was recorded at $29 \%$ of visits. For the majority of young people, partners were of similar age or 1-3 years older. Females were more likely to have an older partner (Table 4). For 6\% of visits where age of partner could be identified, the partner was four or more years older than the young person concerned.

Heterosexual intercourse was stated to have been consensual at $5 \%$ of visits; one visit related to a male client. At two visits, both female, sexual intercourse had not been consensual. For the remaining $95 \%$ of visits there was no
Table 3 Age at sexual debut, when recorded, for both sexes

\begin{tabular}{|c|c|c|c|c|}
\hline \multirow{2}{*}{$\begin{array}{l}\text { Age at sexual } \\
\text { debut (years) }\end{array}$} & \multicolumn{2}{|c|}{ Males } & \multicolumn{2}{|c|}{ Females } \\
\hline & $n$ & $\%$ & $n$ & $\%$ \\
\hline Not recorded & 77 & 77 & 79 & 56 \\
\hline 10 & 0 & 0 & 2 & 1 \\
\hline 11 & 4 & 4 & 5 & 4 \\
\hline 12 & 14 & 14 & 19 & 13 \\
\hline 13 & 5 & 5 & 35 & 25 \\
\hline 14 & 0 & 0 & 2 & 1 \\
\hline Total & 100 & 100 & 142 & 100 \\
\hline
\end{tabular}

record as to whether or not sex was coerced. Alcohol history was recorded for 19 (8\%) clients; one was male. For seven females alcohol was stated as having been a causal influence in sexual activity.

The main reason for each visit and the activities that took place (outcome) were determined. There was no record relating to 26 visits by males $(10 \%)$ and 13 visits by females (4\%). Condoms were requested by $96 \%$ of males and received by $98 \%$. In comparison, $36 \%$ of females requested condoms, 26\% hormonal contraception and $10 \%$ both condoms and hormonal contraception. Of these, $67 \%$ of females received condoms, $18 \%$ hormonal contraception and $37 \%$ both. Overall, $35 \%$ of females were seen for the consequences of sex [i.e. pregnancy testing, emergency contraception, sexually transmitted infection (STI) testing and/or treatment and unplanned pregnancies] and $80 \%$ of these subsequently received condoms and/or hormonal contraception (Figure 1). Twelve percent of females were seen solely for the consequences of sex, with a further $8 \%$

Table 4 Comparison of age of young person with age of partner, when recorded, per visit

\begin{tabular}{|c|c|c|c|c|c|c|c|c|c|c|}
\hline \multirow[t]{2}{*}{$\begin{array}{l}\text { Age of partner } \\
\text { (years) }^{\mathrm{a}}\end{array}$} & \multicolumn{4}{|c|}{$\begin{array}{l}\text { Age of young person (years) } \\
\text { for male visits }(n=55)^{b}\end{array}$} & \multicolumn{4}{|c|}{$\begin{array}{l}\text { Age of young person (years) } \\
\text { for female visits }(n=117)^{b}\end{array}$} & \multicolumn{2}{|c|}{ Total } \\
\hline & 11 & 12 & 13 & $14^{c}$ & 11 & 12 & 13 & $14^{c}$ & $n$ & $\%$ \\
\hline $\begin{array}{l}\text { Younger than } \\
\text { Same age } \\
1-3 \text { years older } \\
4 \text { years older } \\
5+\text { years older } \\
\text { Total }\end{array}$ & $\begin{array}{l}0 \\
2 \\
1 \\
0 \\
0 \\
3\end{array}$ & $\begin{array}{r}0 \\
13 \\
10 \\
0 \\
0 \\
23\end{array}$ & $\begin{array}{r}0 \\
19 \\
8 \\
0 \\
0 \\
27\end{array}$ & $\begin{array}{l}0 \\
1 \\
1 \\
0 \\
0 \\
2\end{array}$ & $\begin{array}{l}0 \\
0 \\
2 \\
0 \\
0 \\
2\end{array}$ & $\begin{array}{r}1 \\
1 \\
10 \\
3 \\
0 \\
15\end{array}$ & $\begin{array}{r}1 \\
31 \\
54 \\
4 \\
4 \\
94\end{array}$ & $\begin{array}{l}0 \\
5 \\
1 \\
0 \\
0 \\
6\end{array}$ & $\begin{array}{r}2 \\
72 \\
87 \\
7 \\
4 \\
172\end{array}$ & $\begin{array}{r}1 \\
42 \\
51 \\
4 \\
2 \\
100\end{array}$ \\
\hline
\end{tabular}

aTerm 'partner' does not necessarily imply 'sexual partner' as it was not always possible to determine this from the case notes.

${ }^{b}$ Age of partner not recorded at 426 visits ( male $=199$, female $=227$ ).

cRefers to young people who were seen both before and after their fourteenth birthday during 2003. 


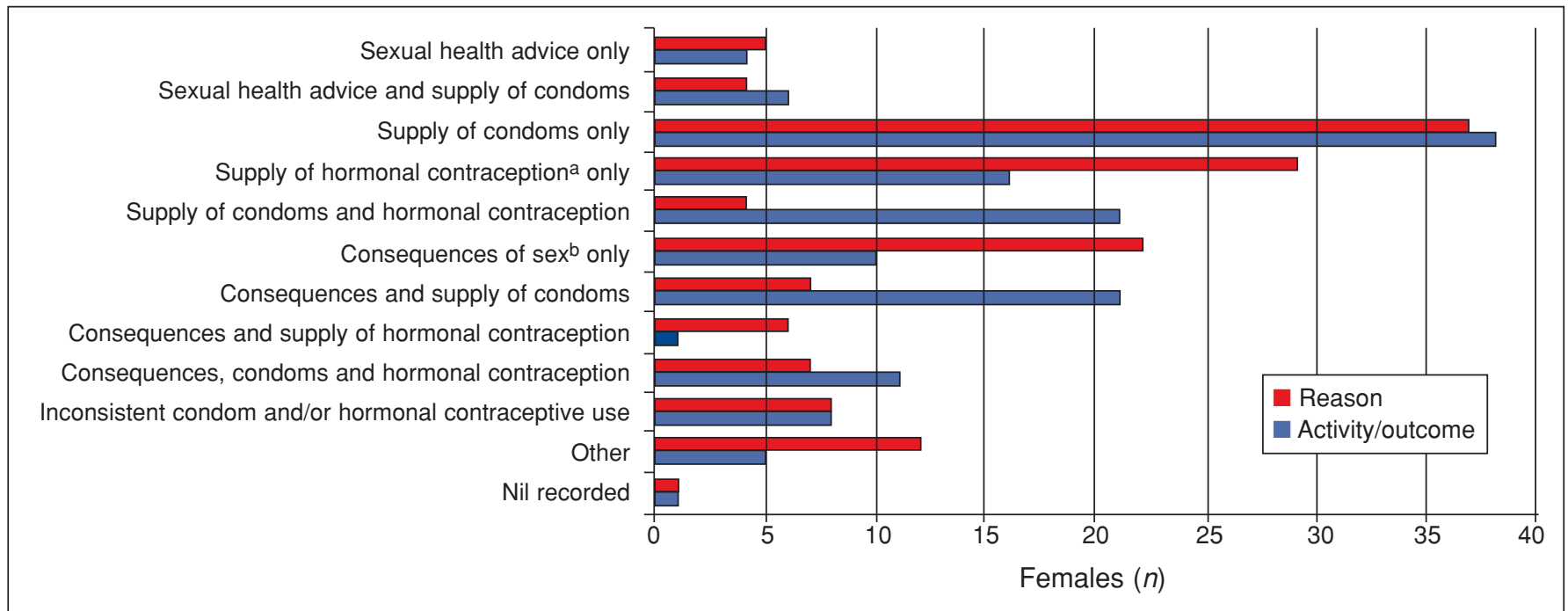

Figure 1 Reason for and outcome of visits of young females included in the study. aHormonal contraception: $40 \%$ of females received hormonal contraception (combined oral contraceptive, 68\%; Depo-Provera ${ }^{\circledR}, 21 \%$; progestogen-only pill, $7 \%$; implant, $4 \%$ ). bConsequences of sex included one or more of: pregnancy testing, emergency contraception, STI screening and/or treatment, and unplanned pregnancy

exhibiting inconsistent condom or hormonal contraceptive use by returning for further consequences of sex. No males were seen for the consequences of sex.

Overall, $96 \%$ of males and $71 \%$ of females were seen exclusively by a nurse. Of the new registrations, $93 \%$ of males and 53\% of females saw a nurse only. At follow-up, $97 \%$ of visits by males and $57 \%$ of visits by females were dealt with by the nurse. Results relating to the identification of markers of sexual abuse and exploitation and to demonstration of compliance with Fraser guidance are reported elsewhere. ${ }^{8}$

\section{Discussion}

Young males are less likely to access sexual health services than females ${ }^{9,10}$ but their attendance is on the increase, primarily for the supply of condoms. ${ }^{10}$ Emphasis has been placed on targeting males to help reduce the incidence of STIs and unplanned teenage pregnancies 11,12 and to making services more accessible to males. ${ }^{12}$ The $41 \%$ male attendance observed in the present study compares favourably with that of others, ${ }^{13}$ and suggests that we are providing a user-friendly service. Our results indicate that young people, especially males, are more likely to use services directed at young people. In geographical areas where both YPCs and FPCs co-exist, 96\% of male and $87 \%$ of female attendances for under-14s are at YPCs.

Where recorded, males were less likely to already be sexually active than females ( $30 \%$ vs $57 \%$ ). In the present study, males start attending clinics at an earlier age than females, thus providing an opportunity to promote positive messages about sex and safe sexual practices and postponing its onset.

The circumstances at first intercourse (i.e. regret, willingness, autonomy and contraceptive use) determine the sexual competence of a young person, as defined by Wellings et al. ${ }^{7}$ Wellings et al. reported that $91 \%$ of females and 67\% males aged 13-14 years were not sexually competent at first intercourse. ${ }^{7}$ We would expect to have recorded whether a young person was sexually active when they first register with our service. This was not the case for $13 \%$ of young people. We did not record whether condom use is consistent. We also recorded very little about a young person's sexual partners: their age, number, whether they are equally willing, if sex is autonomous or if coercion is involved, or whether sex is associated with later regret.
Reasons for poor record keeping might include time constraints, lack of understanding of what is required, concern that asking a young person too many detailed and intimate questions may deter their re-attendance, and health professionals may feel embarrassed about asking intimate questions. Also, the $\mathrm{C}$-card scheme requires minimal information from a young person (i.e. details of sexual history are not required) and uptake of the scheme

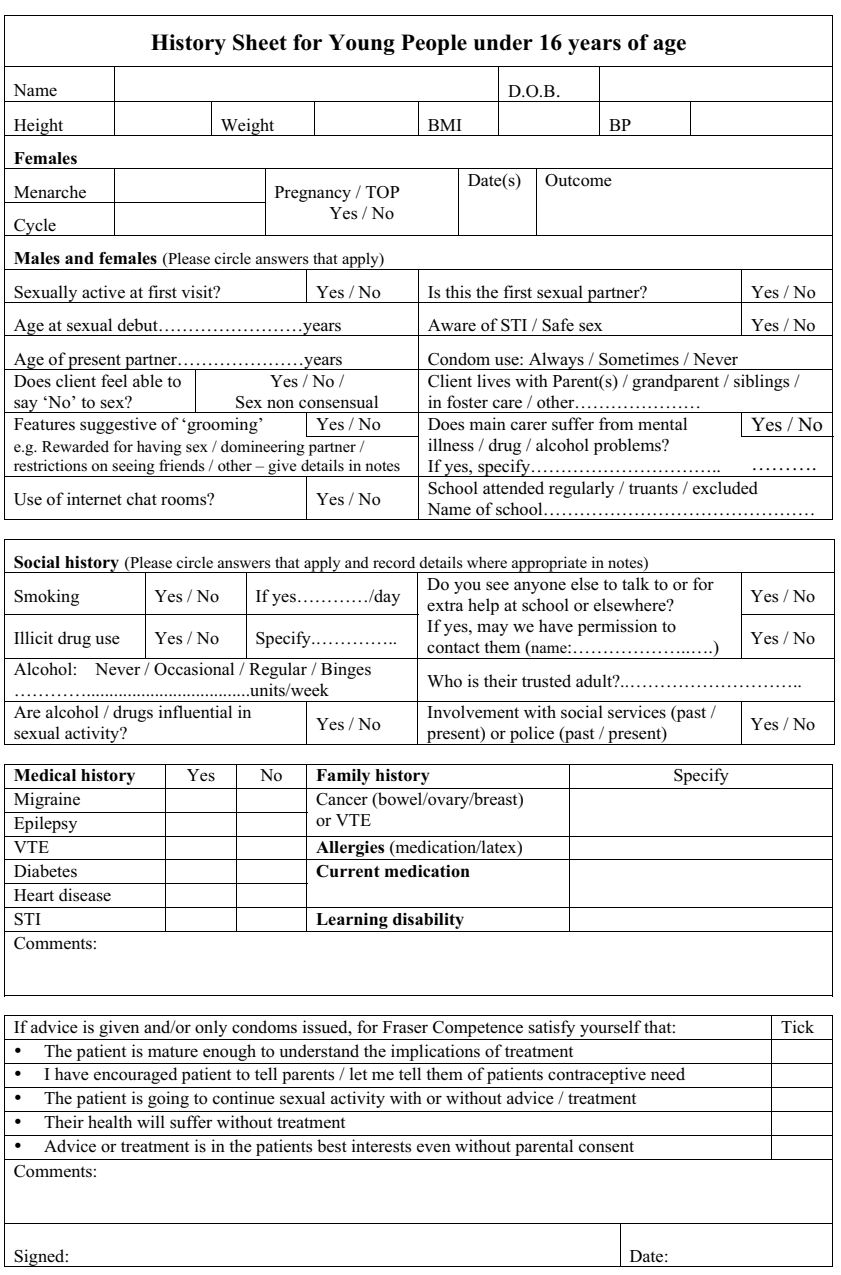

Figure 2 Under-16s gender-neutral history sheet developed by the authors 
is on the increase. It is operated mainly by youth workers who, via their links with education and other youth services, are likely to already know a lot about the young people using this service. In contrast, some nursing staff work within both systems. This may have influenced the lack of sexual history data recorded. It is also likely that where there was no record relating to a visit, condoms alone were supplied under the $\mathrm{C}$-card scheme, as consultations either side of these dates were for this reason.

We were disappointed by our service's poor record keeping and recognise the need to develop tools to prompt the recording of sexual health data that is relevant to males and oriented to under-16s. We wonder if other services would find similar deficits. We are introducing a genderneutral history sheet for all under-16s (Figure 2). As reported elsewhere, ${ }^{8}$ this will be combined with a section for assessment of Fraser criteria in addition to a checklist of potential markers of sexual abuse and exploitation. It is anticipated that this will be completed over a series of visits as we gain the young person's confidence.

The majority of our young people are attending for preventative care: $96 \%$ of males (condoms) and $72 \%$ of females $72 \%$ (condoms and/or hormonal contraception). The reputation of community clinics for STI testing is only recently beginning to develop and we do not have urine testing available. It was therefore unsurprising that no males attended for the consequences of sex (i.e. STIs). Since females become pregnant and have postcoital contraception options, it is inevitable that some will attend for the consequences of sex. Some $35 \%$ of females were seen initially for such consequences rather than to provide ongoing contraception, but $80 \%$ of these subsequently went on to receive regular contraception (condoms and/or hormonal contraceptives). Only $7 \%$ of young females were managed solely for consequences of sex, and a further $6 \%$ who had previously received contraception re-attended with further consequences. This would suggest that we are sending out the right messages to young people.

The Sexual Offences Act $2003^{1}$ allows for nonphysicians (including youth workers) to assess Fraser competence and we encourage this. As well as giving advice, condoms and performing pregnancy tests, nurses can also issue repeat supplies of hormonal contraceptives under patient-specific directions and hormonal emergency contraception under patient group directions. This is likely to account for nurses seeing the majority of under-14s exclusively. We are currently extending the nurses' role to include oral and injectable contraceptives. It is anticipated that this will increase the uptake of regular contraceptive use even further and encourage safer sexual practices.

\section{Conclusions}

Just over half of our clients are sexually active when first accessing our service. The majority are taking preventative action against the consequences of sex. Sexual health details that would allow us to make an appropriate 'risk assessment' of young people are incomplete in our service. This is particularly true for males who represent $41 \%$ of our clientele. It is anticipated that the introduction of a gender-neutral history sheet for under-16s will improve record keeping alongside a continuing education programme for all health professionals but particularly nurses who see the majority of these young people.

\section{Statements on funding and competing interests Funding None identified.}

Competing interests None identified.

\section{References}

1 Sexual Offences Act 2003. London, UK: HMSO, 2003. http://www.opsi.gov.uk/ACTS/acts2003/20030042.htm [Accessed 14 March 2006].

2 The Bichard Inquiry. An Independent Inquiry Arising from the Soham Murders. 2004. http://www.bichardinquiry.org.uk/ [Accessed 18 December 2005].

3 Batty D. Soham inquiry chief criticises teen sex interviews. Guardian 22 June 2005. http://www.guardian.co.uk [Accessed 18 December 2005].

4 Norfolk Area Child Protection Committee. The Bichard Enquiry ACPC Guidance (Provisional). http://www.acpc. norfolk.org.uk/ [Accessed 18 December 2005].

5 Confidentiality of Adolescent Sexual Health Services: Joint Statement (October 2005). http://www.ffprhc.org.uk/admin/ uploads/FinalSignedDJTStatement.pdf [Accessed 28 January 2006].

6 Health Behaviour in School-aged Children (HBSC) Survey. HBCS Briefing Series: 3. Sexual Health. http://www.cmo. wales.gov.uk/content/work/schools/hbsc3-e.pdf [Accessed 19 October 2005].

7 Wellings K, Nanchahal K, Macdowall W, McManus S, Erens B, Mercer $\mathrm{CH}$, et al. Sexual behaviour in Britain: early heterosexual experience. Lancet 2001; 358: 1843-5180.

8 Cook L, Fleming C. Audit of under-14s who attend sexual health clinics in Gwent, South Wales, UK: identifying young people at risk of abuse and exploitation. J Fam Plann Reprod Health Care 2006; 32: 27-30.

9 National Assembly for Wales. A Strategic Framework for Promoting Sexual Health in Wales. January 2000. http://www.wales.gov.uk/ [Accessed 1 April 2005].

10 Pearson S. Men's use of sexual health services. J Fam Plann Reprod Health Care 2003: 29(4): 190-194.

11 Social Exclusion Unit. Teenage Pregnancy. http://www. socialexclusionunit.gov.uk/ [Accessed 18 December 2005].

12 National Assembly for Wales Welsh Health Circular. Best practice advice on the provision of effective contraception and sexual health advice services for young people. WHC (2001) 41.

13 Williams EC, Kirkman RJ, Elstein M. Profile of young people's advice clinic in reproductive health, 1988-93. BMJ 1994; 309: 786-788.

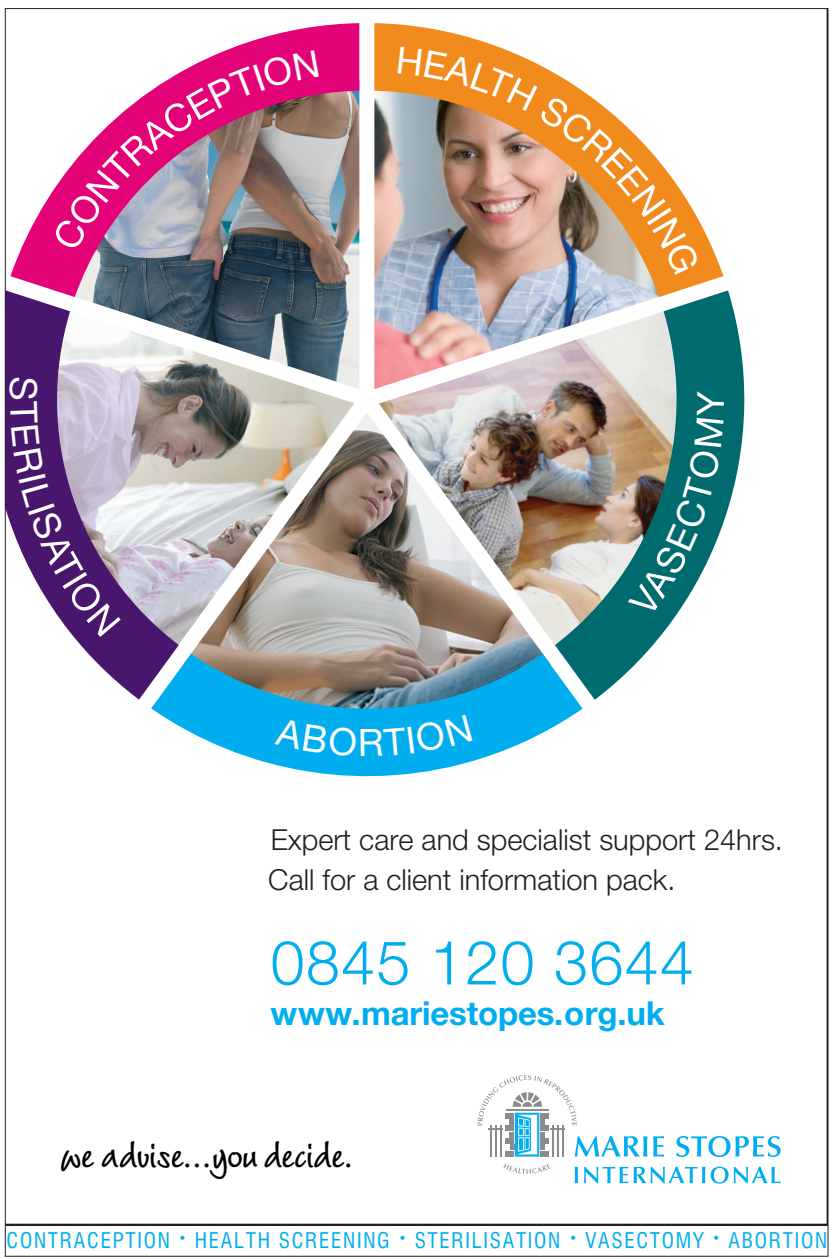

